\section{artelogie}

\section{Artelogie}

Recherche sur les arts, le patrimoine et la littérature de l'Amérique latine

$2 \mid 2012$

Mexique : espace urbain et résistances artistiques et littéraires face à la « ville générique »

\title{
Citámbulos o los laberintos de lo insólito
}

Ana Álvarez, Fionn Petch, Valentina Rojas Loa y Christian von Wissel

\section{CpenEdition}

Edición electrónica

URL: https://journals.openedition.org/artelogie/8002

DOI: 10.4000/artelogie.8002

ISSN: 2115-6395

Editor

Association ESCAL

Referencia electrónica

Ana Álvarez, Fionn Petch, Valentina Rojas Loa y Christian von Wissel, «Citámbulos o los laberintos de lo insólito», Artelogie [En línea], 2 | 2012, Publicado el 21 enero 2012, consultado el 07 enero 2022. URL: http://journals.openedition.org/artelogie/8002 ; DOl: https://doi.org/10.4000/artelogie.8002

Este documento fue generado automáticamente el 7 enero 2022.

Association ESCAL 


\title{
Citámbulos o los laberintos de lo insólito
}

\author{
Ana Álvarez, Fionn Petch, Valentina Rojas Loa y Christian von Wissel
}

Texto a ocho manos y cuatro cabezas Salir, detenerse, mirar, escuchar, desconocer, perderse, reconstruir, oler, imaginar la Ciudad de México.

\section{El inicio}

\section{Omnipresente}

“Cuando la gente está alterada de los nervios, cuando ya no duerme, ya no puede reconciliar el sueño, cuando anda toda temblorosa, exaltada, alterada, déle a tomar las auténticas tabletas de piel de toro..."

VR: Sólo que en vez de "tomar las auténticas tabletas de piel de toro", nosotros propusimos "convertirse en citámbulo".

2 AA: Acercarse a la ciudad que yace lejos de los prejuicios, propios y ajenos, que homogeneizan y despersonalizan a la ciudad fue el origen de Citámbulos, un colectivo interdisciplinario que en 2003 comenzó a recorrer las calles de la Ciudad de México, a dialogar con sus habitantes y dejar que la mirada subjetiva sugiriera nuevas lecturas, para con todo ello construir una nueva cartografía de fenómenos urbanos que los propios habitantes solían (y suelen) pasar por alto en el transcurrir de lo cotidiano.

FP: Lo que me fascina de los comienzos del proyecto es como todo surgió de una manera tan orgánica, casi sin proponérnoslo: fue la coyuntura de amistades, de disponibilidad de tiempo - y, creo, de estar viviendo en el centro histórico de la ciudad en un momento clave en su desarrollo, antes de la transformación que actualmente vive. Nuestro acercamiento no involucraba posiciones académicas ni la intención de crear un producto específico, al contrario, simplemente empezamos a caminar... La actitud era una - muy sana - de ingenuidad: creo que en este entonces ninguno de nosotros había escuchado hablar del dérive o de la psicogeografía. Y en algún momento alguien dijo "debemos escribir un libro..." 
4 CW: Caminata, paseo, deriva... Creo que es importante mencionar que no ubicábamos nuestras deambulaciones por la ciudad dentro de ninguna práctica artística, sino dentro de una práctica de crítica aplicada: "dudo, por lo tanto ambulo, por lo tanto existo".

5 AA: Es verdad, había mucha frescura y muchas ganas de conocer directamente la ciudad que habitábamos, pero también es cierto que leímos mucho, escribimos manifiestos, teorizamos sin perder de vista que el ejercicio central era salir a la calle, explorar la ciudad.
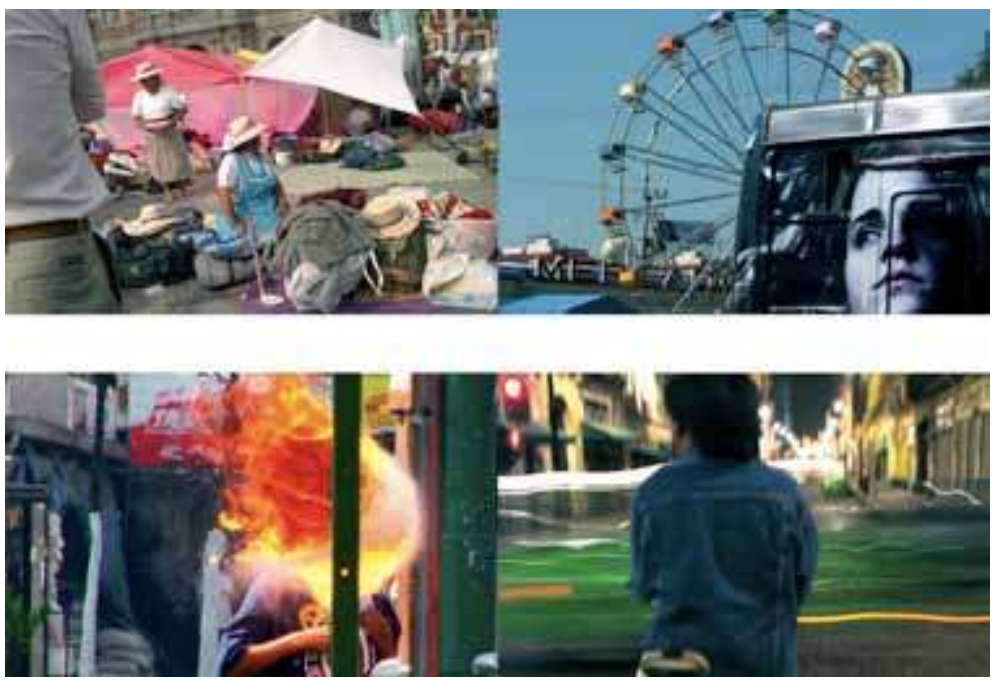

\section{Lo insólito}

\section{Paseo dominical por la Alameda central}

“Al sentir que la ciudad lo avasalla, deténgase en sus detalles y la descubrirá vulnerable, compleja, compuesta por cientos, quizá miles de microhistorias en mosaico. Tome una de esas piezas y persígala, a ver a dónde lo lleva..."

\section{Mapas de Flor Marín}

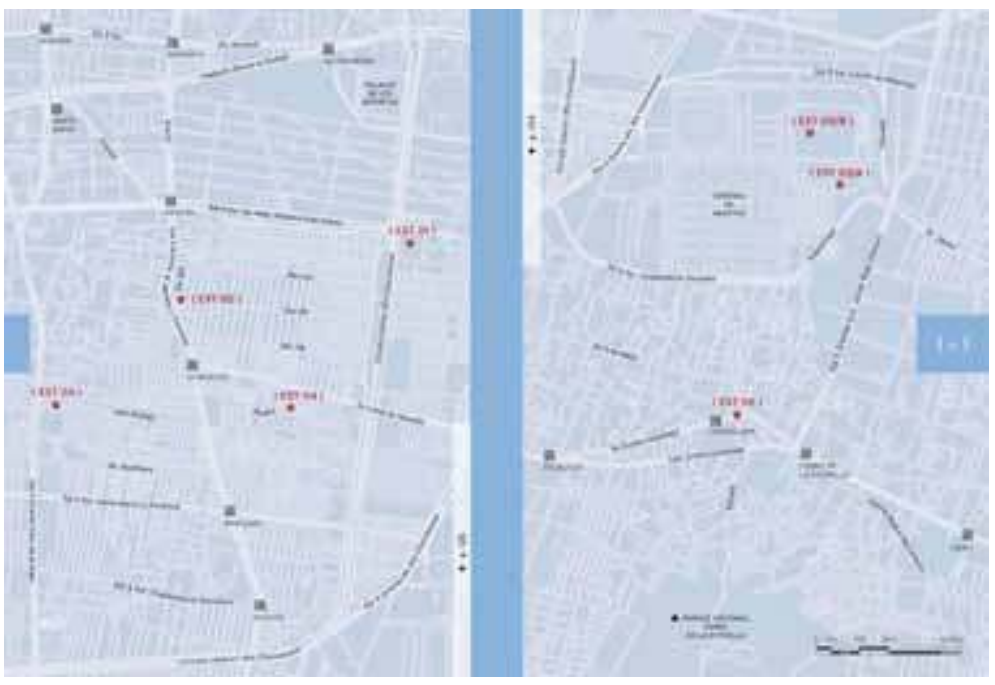


6 AA: Así precisamente fue como se construyó este texto y muchos otros de la guía. Digamos que la guía fue, en un cierto sentido, una suma de encuentros fortuitos que la ciudad y sus habitantes nos regalaban: como el de un biólogo que nos contó que el mural del Hombre controlador del universo de Bellas Artes tenía dibujadas las treponema pallidum causantes de la sífilis y después coincidimos con un médico que había escrito al respecto. Dialogar con los habitantes se convirtió también en una manera de "tejer" los fenómenos y espacios de la ciudad.

7 VR: La ciudad siempre nos sorprendió, a veces en los rincones más conocidos, otras veces en las numerosas tierras incógnitas de la Guía Roji. Había mañanas en las que ése era el ejercicio: mirar el mapa, buscar una parte de la ciudad en la que nunca habíamos estado y lanzarnos para allá, así, sin ninguna preparación. Entonces había que empezar a caminar, a mirar, hurgar, escuchar, siguiendo las pistas de nuevos laberintos. No hubo una sola vez en la que saliéramos a la calle y no juntáramos material para ponernos a escribir.

8 AA: Bajo la premisa de que es la mirada, el imaginario, lo que se homogeneiza y no la ciudad, Citámbulos apostó por establecer una relación más epidérmica con la ciudad: salir, encontrar, perderse, oler, escuchar, interpretar, escribir, fotografiar, para armar una guía de asombros de la ciudad de México, en la que el transcurrir de lo insólito aquello que corre en paralelo a la vida cotidiana pero que para "descubrirse" experimentarse desde otro ángulo - estuviera de manifiesto.

CW: La manera cómo se piensa la ciudad condiciona cómo se construye. Sin embargo, aunque estas palabras se hayan dicho antes, pocas veces se han tomado en serio y se han buscado maneras alternas de pensar la ciudad. Al principio salíamos sin tener muy claro qué estábamos haciendo, pero nuestros pies lo sabían major: caminar la ciudad es pensar y construirla de una manera distinta a la propuesta por el discurso dominante: que la ciudad es rojo peligro y gris (o ¿azul?) genérico... Nuestros pies, en cambio, nos enseñaron que la ciudad es multicolor - y además de serlo está en perpetuo proceso de transcolorisación...

\section{El Rincón del ahorcado}

"La puerta abierta de un edificio me invita a pasar. Adentro, donde la sombra corta de tajo luz y calor, una serie de miradas furtivas me recorren, produciéndome la sensación de haber traspasado una de las tantas fronteras invisibles que dividen esta ciudad de ciudades..." 


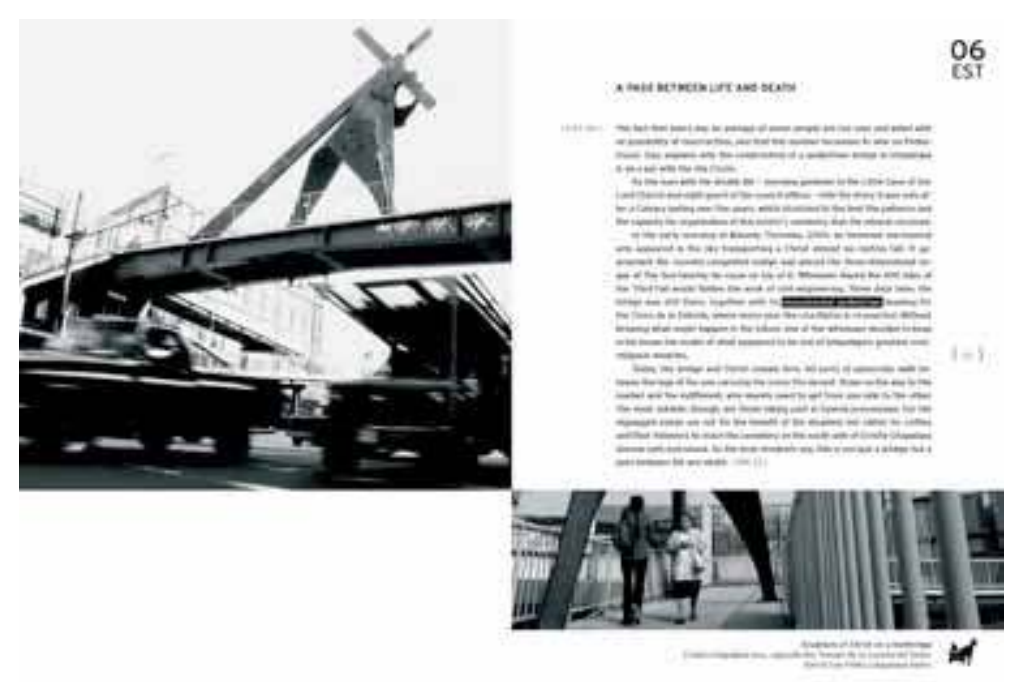

10 CW: Tal vez, ésta sea la mejor cura contra la ciudad genérica: una puerta abierta que muestre que la ciudad es mucho más que su apariencia (supuestamente liberada de identidad). Ver a través de puertas abiertas también demuestra que Rem Koolhass es arquitecto: su mirada tiene puestos los lentes de la obsesión con el entorno construido, en vez de tomarse el tiempo para ver a la gente que viva adentro. ¿Cómo puede ser una ciudad genérica si cada una/uno de sus habitantes es único?

11 AA: Realizar la guía, platicar con los habitantes, preguntar qué tiene de entrañable la ciudad que habitan arrojó las razones por las que no sólo se sobrevive la urbe, sino se vive y disfruta: todos tenemos un rincón, un personaje, un objeto, una historia que hace que esta ciudad sea ésta y no cualquier otra. El libro y sus lectores, demostraron que una ciudad mantiene una identidad propia si invita a imaginar, si permite establecer una relación subjetiva, en la que cada quien encuentra su propia manera de relacionarse con ella. Lo que el libro propone, a pesar de dar las coordenadas específicas de los espacios y situaciones elegidas, es que cada quien encuentre o arme su propia guía de asombros.

\section{La mirada}

\section{Microcosmos}

"La jungla de concreto se quiebra cada primavera y un mundo apenas sospechado por los habitantes de la metrópolis en las grietas de las banquetas y los terrenos baldíos." 
WST 10: imagenes de Gabriel Pérez

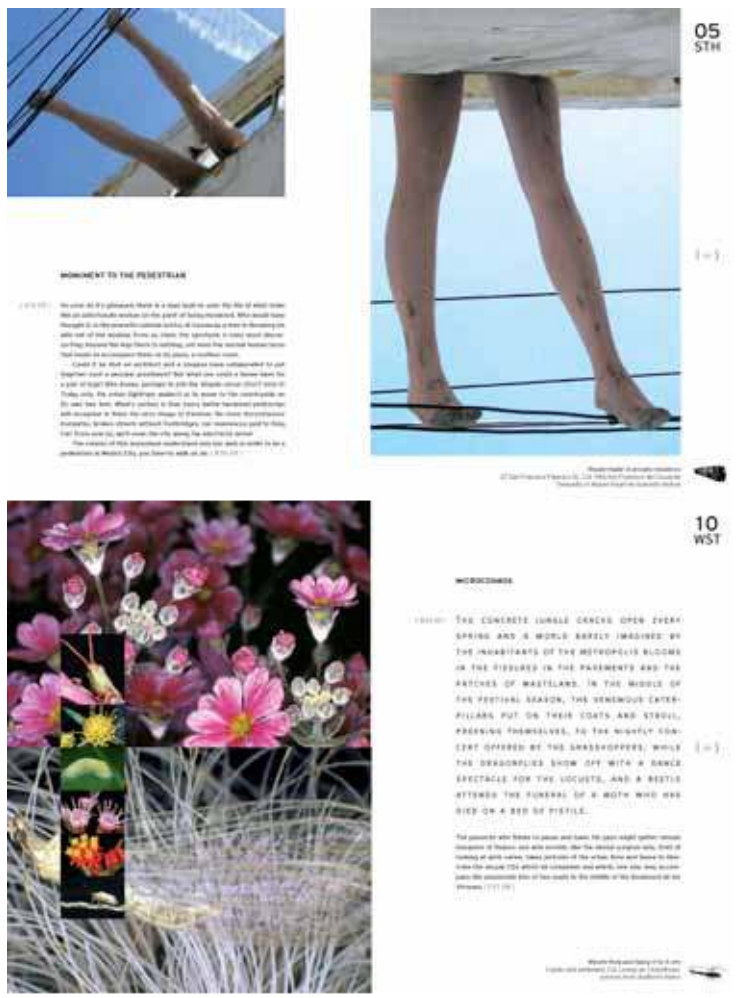

12 VR: La mirada es viajera. Puede trepar por los cables de electricidad, abarcar el horizonte, husmear por ventanas entrecerradas, hurgar en las grietas de las banquetas, caerse en un hoyo o perderse en el cielo. Para nosotros era muy importante darle rienda suelta a la mirada, permitiéndole que viajara en escalas y lugares poco explorados en nuestro devenir cotidiano.

13 AA: Las múltiples maneras y escalas de ver la ciudad nos las revelaron también las múltiples profesiones y oficios que en ella se practican: como el dentista que se aburre de ver caries y decide pasar sus ratos de ocio tomando más de 3,000 fotografías de la flora y fauna "microscópica" que habita en las grietas de las banquetas y los terrenos valdíos.

\section{Palimpsesto}

"Se supone que la calle es un fenómeno del espacio y no del tiempo, pero deambular a determinadas horas por el Centro... parece demostrar lo contrario. Porque conforme el reloj avanza en el corazón del Zócalo, en las calles aledañas los senderos se bifurcan, las esquinas se multiplican y sobre la traza Méxicorenacentista se dibuja un nuevo mapa...: callejón del moño, $1^{a}$ cerrada de discos, bulevar de los calzones, circuito de relojes y avenida del peluche." 


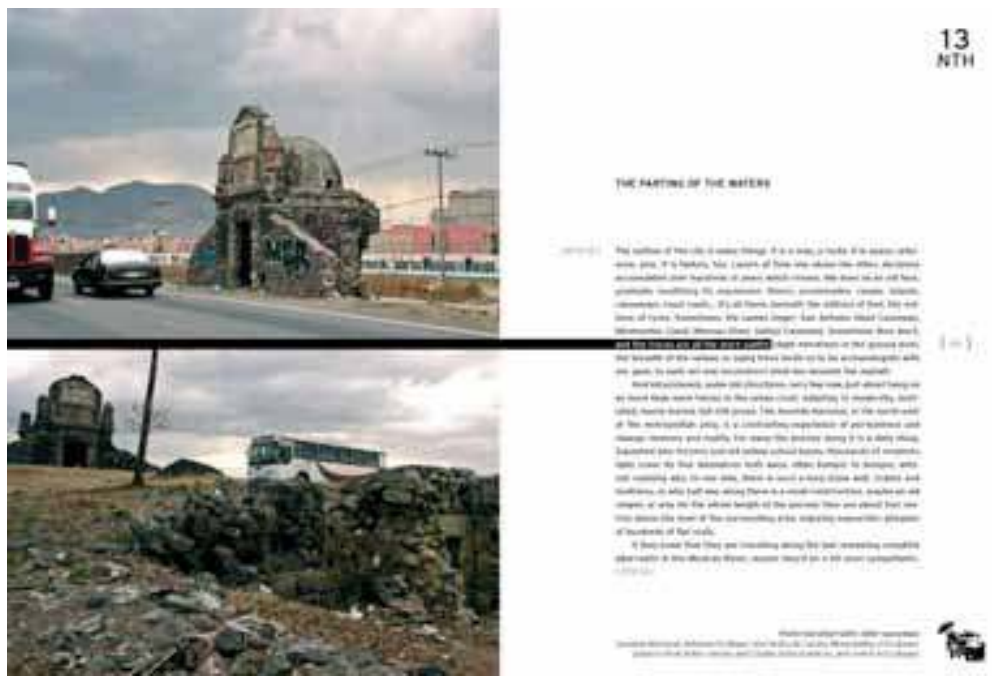

FP: Cuando escribí el primer borrador de este texto, lo llené de los datos históricos que había investigado acerca de la traza que hicieron los españoles del primer cuadro de la ciudad, y su superposición a la antigua retícula de canales de Tenochtitlan. El resultado fue un poco aburrido... El desafío de los textos de la guía era escribir de una manera que aprovechara nuestras fuentes al máximo, pero que volara también por encima de ellas, como si las fuentes fueran un apuntalamiento invisible. El trabajo en equipo, en donde cada texto pasaba por múltiples revisiones en conjunto y por separado, fue clave para lograr esta ligereza.

CW: Ser honesto con la ciudad y sus habitantes - pero también con nosotros. Tratar de capturar diferentes perspectivas y capas de significado, a veces complementarias pero otras veces contradictorias. Escuchar - también con los ojos - con respeto y sostener el diálogo en la confianza de poder decir lo que uno piensa... Más tarde, sobre la base de la guía buscábamos traducir estos principios en una exposición al trabajar con más de 120 personas, es decir, al incorporar y sobreponer más de 120 maneras de caminar y ver la ciudad. El palimpsesto, sin duda, es la antítesis de la ciudad genérica.

\section{Las voces}

\section{Tianguis nocturno}

"Son las tres de la mañana y en las naves principales de la Central de Abastos aún no se han levantado las cortinas de metal. El abecedario de pasillos, con su penetrante olor a chiles, el rechinar de sus bandas para transportar naranjas y el enloquecido ir y venir de treinta mil compradores, yace desierto. Afuera, en cambio, en el patio trasero del mercado más grande de América Latina, transcurre el cotidiano pero intenso encuentro del campo con la ciudad. [...] Todavía en la periferia, el español se mezcla y confunde con el náhuatl..."

Este medio no se puede ver aquí. Por favor refiérase a la edición en línea http:// journals.openedition.org/artelogie/8002

VR: La exploración de la ciudad mediante los sentidos más allá de la vista, no fue solamente la oportunidad de liberarnos de la dictadura de la mirada, también fue la 
oportunidad de explorar muchos otros paisajes: paisajes sonoros, gustativos, táctiles y olfativos.

CW: Esa era la ciudad que Citámbulos salía a buscar: la que se mezcla y se confunde, la que está en la periferia, pero en la periferia de nuestra percepción. Ahí la ponemos, a veces por miedo, otras por necesidad, pero también porque hay conflicto. La ciudad de las múltiples voces es también la de las múltiples concepciones del mundo y éstas a veces se confrontan. Pero solo si se busca entender estos choques, si uno se toma la molestia de escuchar al otro y explorar su manera de nombrar el mundo, hay vida.

\section{La risa}

\section{American Way of Belief}

"Si usted oye la voz de Cristo, favor de no salir del baño hasta que termine de oír la voz..."

\section{STH 03: texto de Gabriel Rodríguez}
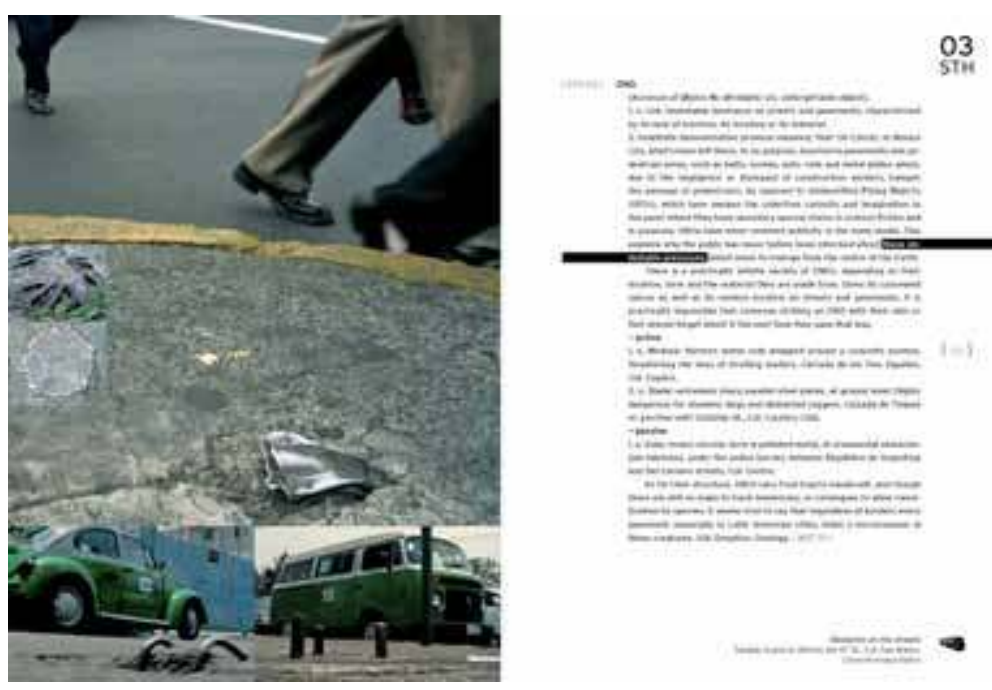

VR: Vivir la urbe con humor es necesario no sólo para sobrevivirla, sino también para celebrarla y disfrutarla. Además de escribir nuestros textos con el humor como ingrediente fundamental, una parte importante fue documentar algunos de los muchos momentos de humor involuntario que tiene la ciudad.

FP: Esta noción de la sobrevivencia fue clave en nuestra concepción de la guía: la necesidad de cambiar la propia perspectiva para enfrentar así algunas de las experiencias a veces conflictivas que tiene esta ciudad. En este sentido, creo que propusimos un metamorfosis en la figura del flâneur, mejor ajustado a la megalópolis de hoy. A diferencia del caminante de Baudelaire, que observa la ciudad desde una perspectiva distanciada de diletantismo burgués - buscando novedades a partir de un cierto aburrimiento en su experiencia de la ciudad - ser un citámbulo en México es una disciplina necesaria para hallar lo extraordinario y maravilloso en un cotidiano apabullante. Disfrutar de estos respiros es lo que hace la ciudad vivible.

CW: El derecho de celebrar y disfrutar la calle es, como dijo Alfonso Morales, un derecho fundamental al cual muchos habitantes de ésta y otras ciudades han renunciado. La consecuencia de esta renuncia es la pérdida no sólo del espacio público, 
sino también de la experiencia del propio cuerpo en la ciudad. Porque con el cuerpo nos posicionamos en el espacio y es tanto el punto de partida de nuestra perspectiva como el objeto de la vista de los demás. Si este cuerpo ya no festeja su existencia, sino que sólo opera (es decir, cuando carga la vida en vez de ser de vida), entonces el cuerpo se convierte en máquina y la calle en una cadena de montaje de un trabajo muy mal pagado.

VR: Otra de la grandes diferencias entre citámbulo y flâneur es que el citámbulo se asume como habitante. Como habitantes, traemos nuestro bagaje de prejuicios, de expectativas, y en una ciudad tan segregada como ésta, nuestra condición de jóvenes, blancos y de clase media inevitablemente desencadena una serie de reacciones en los demás. Lo que decidimos hacer entonces fue asumir que para poder preguntarle a alguien quién es, primero tienes que estar abierto a que te pregunte quién eres tú y por qué estás de preguntón.

\section{El delirio}

\section{Yo podría bailar ese sillón dice Isadora dice Julio}

"(¡Querido lector!), aunque el asunto ya se muestre terriblemente complejo, no basta. No se trata sólo de la inter-existencia de las cosas, fenómenos y significados sino también de su inter-dinámica (su destino interno y dinámico, diría Cortázar).

Así, por lo menos, lo quiso demostrar Isadora Duncan cuando se puso a "bailar un sillón”, es decir, a representar el objeto que es un sillón a partir del movimiento que el sillón provoca en sus usuarios.

Planck y Einstein lo demostraron a través de la física cuántica: la luz se manifiesta al mismo tiempo como partícula y como onda, dependiendo del experimento que se realice. Posición estática y movimiento a la vez. Cosa que es lo que es porque también es otra cosa Isadora y Julio, desde sus tumbas, las verdaderas y las falsas, sin duda apoyarían tal dualismo en el pensamiento de los habitantes de la ciudad."

Este medio no se puede ver aquí. Por favor refiérase a la edición en línea http:// journals.openedition.org/artelogie/8002

VR: Y no es que la verdad siempre tenga que ser delirante -aunque la misma noción de "verdad" lo sea-pero la ciudad constantemente demuestra que el universo tiene mucho de cortazareano: la luz es onda y es partícula, la calle es calle y es hogar, y un sillón es símbolo de inmovilidad y movimiento.

La combinación de una matemática, un filósofo (escocés), un arquitecto (alemán: muy importante por aquello del "delirio filosófico"), una literata, un experto en cuevas y chichones y un dentista-compositor de música de piano resultó, sin lugar a dudas, una gran combinación.

FP: El hecho de que el equipo estuviera conformado por dos extranjeros y dos nativos fue clave en el desarrollo del proyecto - cada grupo ayudó al otro a quitarse sus propios prejuicios respecto a la ciudad. Los nuevos ojos que trae un extranjero obligan al lugareño a volver a ver lo que se había vuelto ordinario; y como nativo evitas que el forastero caiga en la viejo trampa de muchas guías de viaje que únicamente celebran lo meramente kitsch o lo exótico. 
29 AA: Visto en retrospectiva y pensando en el tema del impacto de la globalización en las ciudades, que muchas veces se traduce en homogeneización, creo que esta conjunción de nacionales y extranjeros también es muestra de algunos de los resultados positivos de la globalización, o al menos puede apuntar a maneras en las que la globalización contribuye a recuperar la identidad de las ciudades y no a perderla. Como bien dice Fionn, esta doble prespectiva quitó prejuicios y dio volumen. Sin alguno de estos dos ingredientes (nacionales y extranjeros) creo que la guía hubiera resultado plana.

\section{La acción}

\section{La esquina de la magia}

"Qué vida sería si cada quien Ilevara siempre consigo una silla para descansar cuando la ciudad se lo demanda y qué mejor lugar que la esquina de Av. Revolución y Av. Jalisco para poner esta silla, sentarse a gusto y disfrutar del cine más grande de la ciudad."

Este medio no se puede ver aquí. Por favor refiérase a la edición en línea http:// journals.openedition.org/artelogie/8002

31 AA: Ser observador, pero también llevar a cabo acciones en la ciudad, interactuar con ella, intervenirla, interpelarla, es una manera de conocerla, pero sobre todo de apropiarse de ella. Si tuviéramos que decir cuáles fueron los antecedentes del proyecto Citámbulos habría, ante todo, que hablar de las "acciones" que junto con otros colectivos y enloquecidos de la ciudad realizamos antes de comenzar con la guía, por ejemplo: Jolly Jumper Jumping Sundays, una sesión fotográfica de brincos en distintos puntos de la ciudad o el conjunto de intervenciones en una vecindad a punto de ser derrumbada. En un cierto sentido, la guía comenzó no como un proyecto de libro, sino como un proyecto de acción sobre la ciudad que después se tradujo en libro, más adelante en exposición y, quién sabe, tal vez en un futuro en ópera...

CW: el "descansar" como "acción" - me sigue gustando este giro que se le puede dar a las cosas (a las sillas en particular, pero también a la calle). El "hacer ciudad" está en los deseos que tenemos para la urbe volviéndolos realidad.

El sociólogo C. Wright Mills presentó la "imaginación sociológica" como la capacidad analítica de vincular las luchas personales con las estructuras sociales colectivas. De la misma manera, la "imaginación urbana" será la capacidad - y la acción - de cada uno de nosotros de vincular nuestra existencia con el gran conjunto de relaciones del cual formamos parte: la ciudad (de México).

\section{La resistencia}

\section{En todos los sentidos}

“Adentro, el sonido de un par de codos raspando una superficie rugosa. Afuera, el rasguño odorífico de chiles La Costeña. A lo lejos, la colmena gris de Ecatepec.

Arriba, los manifiestos de Marinetti y Mies van der Rohe. Abajo, Francis Alÿs moviendo dunas. A un lado, las torres de vigilancia. Al otro, los trabajadores. En medio, los 
camiones. Afuera, las cebollas. Adentro, los envases. De cerca, la producción. De lejos, el consumo."

NTH 13: imágenes y texto de Rodrigo Remolina
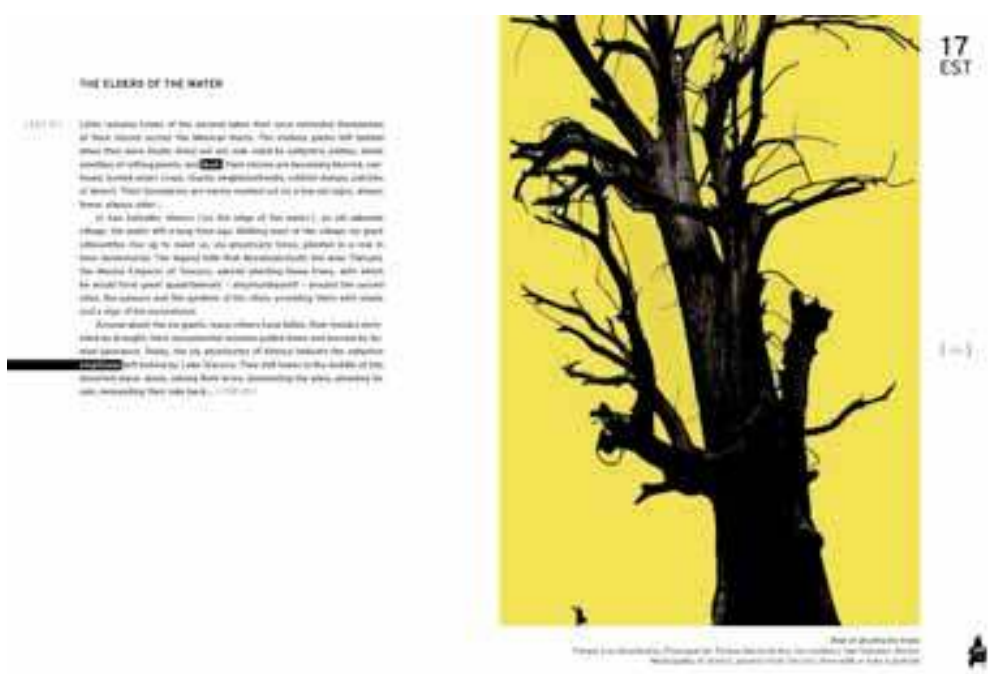

VR: Así como cada historia tiene un género literario en el que mejor puede contarse, cada lugar de la ciudad tiene su propia voz y requiere de un género literario particular para relatarlo: poemas, guiones cinematográficos, novele policiaca, relato periodístico, cómic, haikus...

La literatura es un modo de "resistencia" porque historias que de otro modo quedarían silenciadas por el recuento de una historia monolítica, en la que hay una sola voz y una sola versión de las cosas, pueden ser contadas.

AA: Tal vez esto también demuestra que una urbe de esas características difícilmente puede llegar a ser una ciudad genérica: existe diversidad en demasiados planos (económica, social y cultural) como para ser homogeneizada.

FP: Justamente lo que la guía logra socavar es la noción de un discurso dominante que pretende retratar la ciudad en conjunto y sacar conclusiones acerca de su 'esencia'. Sí es un retrato, pero la multiplicidad de perspectivas se antoja infinita. La selección de 121 perspectivas es casi arbitraria; al escogerlas solamente buscamos equilibrar la distribución geográfica, social, de actividades...

\section{El gran teatro del mundo}

“Mundo Entretenimiento. Mundo Estacionamiento. Mundo Enajenamiento. Mundo Escenografía. La periferia se ha rebelado a su condición. Si se alejó de la ciudad por desprecio o por necesidad, para realizar el sueño de la casa con jardín o para hacer un aterrizaje en paracaídas de emergencia, no importa. Orgullosa, interpreta y construye su plaza de cartón: exclusiva y limpia. Le pinta un cielo que no cambia nunca de color ni de humor... pero sobre todo, se cuida de no poner una ventana donde se pueda colar la realidad." 

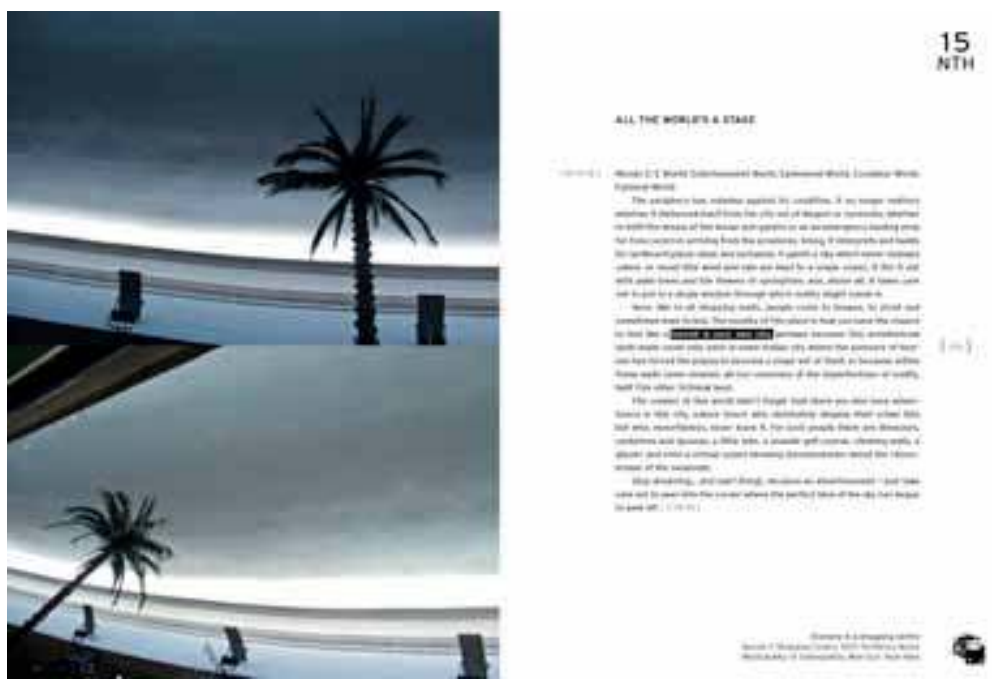

AA: La guía de asombros que Citámbulos propone es una forma de resistencia a la ciudad genérica en tanto apuesta por una relación de no-consumo con la ciudad. Se trata de establecer una relación significativa con la ciudad sin tener que consumir, ni siquiera productos culturales: no se trataba de una guía para ir a museos y teatros, y en un cierto sentido tampoco para visitar lugares, se trata más bien de proponer muchas maneras de ver y encontrarse con los distintos fenómenos, efímeros y permanentes, que componen a la vida cotidiana de la ciudad.

CW: De acuerdo con la importancia del no-consumo. Sin embargo, Néstor García Canclini postula que hoy en día es a través del consumo que uno ejerce su ciudadanía...

41 AA: También creo que la apuesta por el espacio público, por ejemplo vía la crítica de lugares como mundo $\mathrm{E}$, es una forma de resistencia a la ciudad genérica.

Pueden existir lugares como la Condesa, que está totalmente gentrificada, pero en una megalópolis lo que sucede en la calle difícilmente puede homogeneizarse. Un ejemplo interesante de eso es el Centro Histórico, el cual, a pesar de su regeneración no ha sido del todo gentrificado.

CW: Sí, el proceso es distinto pero aún así es un proceso de gentrificación. Tal vez la parte del Centro que le pertenece a Carlos slim es el máximo ejemplo de gentrificación, en tanto representa la intención de convertir un barrio en logo de sí mismo. Lo que viene siendo la Barcelonificación -además de que en el Centro de la Ciudad de México uno se siente en Barcelona- siempre y cuando no se abran las puertas y se descubra lo que hay detrás de las fachadas...

\section{El apocalipsis}

\section{Perra ciudad}

“Caminando por la orilla de la supercalzada alcancé a ver la entrada desde lejos: un hueco en el suelo, una simple escalera al infierno -ya podía escuchar los gritos de la gente asesinada y violada allá abajo. Pero antes de entrar (y prometo que tenía planeado sólo bajar la escalera pero jamás cruzar el túnel) pasó algo inesperado: antes de llegar a la escalera se abrió otro hoyo y de la obscuridad de la tierra salió un señor que me saludó. Toda cosa tiene su chiste, me explicó, aunque sea un túnel peatonal de Tlalpan." 


\section{Santo Demon}

"BLUE DEMON:La ciudad peligra, Santo.

SANTO: Pero... acabamos con el mal, ¿recuerdas?

BLUE DEMON: No, Santo. La lucha sigue."

INR 22: imágen y texto de Onnis Luque

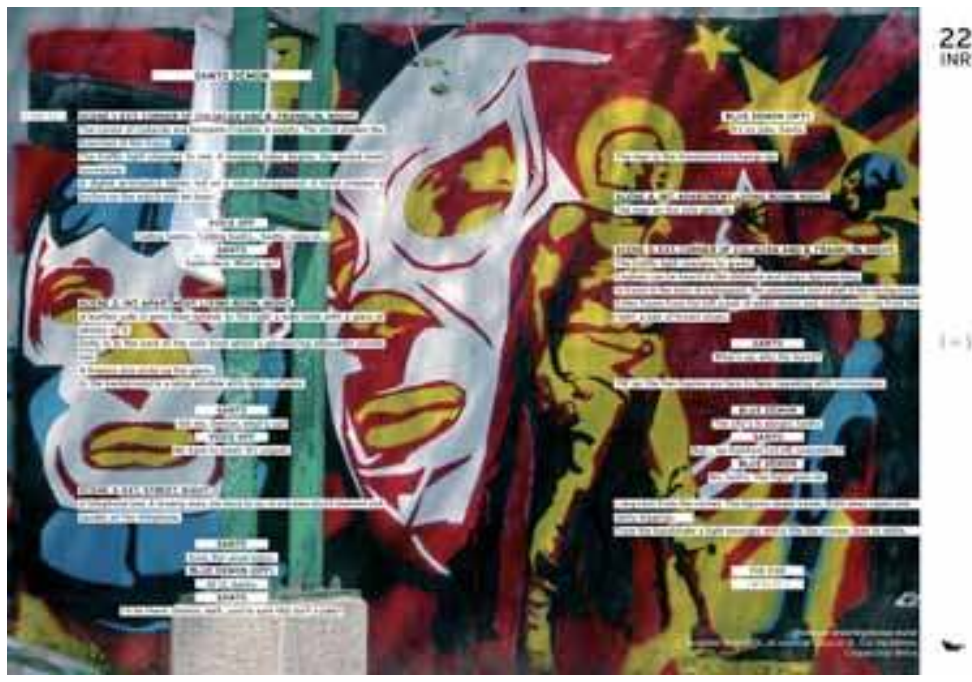

AA: Ciudades como la de México, no sólo deben enfrentar y resistir a la ciudad genérica y la homogenización globalizada, también deben resistir la hegemonía de un discurso, el de la paranoia y el malestar, así como la presencia de un imaginario colectivo que niega matices y volúmenes: el de la catástrofe inevitable.

Sin embargo, el imaginario apocalíptico al que la guía se enfrentó en sus inicios (2003) ha cambiado. La Ciudad de México ha dejado de ser, en el discurso y también en la realidad, el Moloch que devora a sus hijos. No sólo porque el resto del país y de otras ciudades, como Monterrey, viven bajo el terror real y discursivo, así como bajo el caos que la ausencia o incompetencia del Estado y sus instituciones produce (como es el caso de Ciudad Juárez), sino porque la ciudad ha creado maneras de hacerse más habitable sin renunciar a lo que es.

CW: El giro es de la ciudad-horror a la ciudad-refugio en un país-horror... y eso provoca que ahora sea otro tema el que emerja a la superficie y atraiga resistencias: el de la generificación (debido al comercio ubicuo, y no gentrificación como respuesta a la paranoia, como se podría haber leído antes). Pero ¿qué implica este fenómeno?: ¿que la ciudad de México ahora es más burguesa?, ¿o que el país lo es menos? Lo interesante es que en términos "reales" los índices de crimen en la ciudad no han cambiado....

FP: Como extranjero, al llegar a la Ciudad de México por primera vez me fascinó la ausencia de la "museificación" de la ciudad, fenómeno que es regla general en toda Europa. La congelación de una "imagen" ficticia lleva a la pérdida de vida espontánea en las ciudades históricas. Sin embargo, desde que iniciamos el proyecto esta ausencia de "museificación" ya no es el caso: el Centro Histórico es cada vez más pulcro, aunque por otro lado, también es cierto que la ciudad nos parece más habitable. ¿Quién cambió: la ciudad o nosotros? 